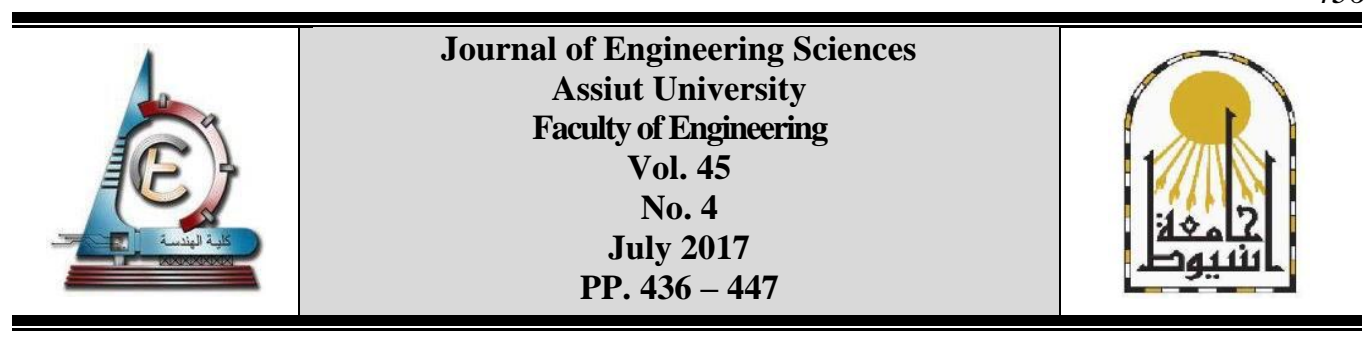

\title{
MODELLING HOURLY ATMOSPHERIC STABILITY AND MIXING HEIGHT USING METROLOGICAL SURFACE DATA
}

\author{
Ragab EISayed Rabeiy \\ Faculty of Engineering, Assiut University, Egypt \\ E-mail: rrabeiy@aun.edu.eg
}

Received 15 May 2017; Accepted 22 June 2017

\begin{abstract}
Atmospheric stability and surface boundary layer or Mixing Height (MH) are essential parameters in modeling of transport and diffusion of pollutants in the atmosphere. The thickness of mixing layer, plume rise from stakes and dispersion coefficients are depending mainly on the category of atmospheric stability at the time of estimation. In this study the Auxiliary Meteorological Model is used to estimate hourly atmospheric stabilities and heights of mixing layer using routinely measured metrological data in Assiut city; Egypt. The model determines Pasquill-Gifford atmospheric stability categories using observations of wind speed, incoming solar radiation, cloud cover and daytime. The results showed that the dominant category in day hours is the stability A especially in Summer and Fall seasons, while in the dark hours the dominant is the very unstable condition (stability F). For the height of mixing layer, $26 \%$ of the estimated values were less than $1500 \mathrm{~m}$ at stability A. While $53 \%$ at stability B, $77 \%$ at stability C, $94 \%$ at stability D, $100 \%$ at stability E, and $100 \%$ at stability F were less than $1500 \mathrm{~m}$. The main conclusion from this research is that the thickness of mixing layer is very small during dark hours for long periods thus increase the levels of pollutants on the ground surface. Therefore, industrial plants should decrease its activity during night hours as possible as they can or at least working with the minimum load of production.
\end{abstract}

Keywords: Atmospheric Stability, Mixing Layer, Air Dispersion Modeling, Meteorological data, Solar Radiation

\section{Introduction}

One of the most important meteorological input parameters into air pollution models are the atmospheric stabilities and atmospheric boundary layer or Mixing Height (MH) [14]. Also these factors are used in other field such as study wind turbine and atmospheric cooling efficiency $[5,6]$. The atmospheric boundary layer is the layer where interactions take place between the earth's surface and the large scale of atmospheric flow [7, 8]. Pollutants are mixed uniformly throughout this layer by turbulence, and turbulent mixing can be either convective or mechanically [9]. Convection occurs during the day-time, when air is heated from below by warm surface of the earth. Mechanical turbulent results from the shearing forces produced when the wind blows over the surface of the earth [10]. At ground level, the wind speed is zero, and it reaches maximum values usually at thousands of meters above the surface. Mechanical turbulence increases with increasing wind speed and is greater over rough surfaces than over smooth surfaces [11]. The amount of turbulence can be categorized into stability classes. 
The most commonly used atmospheric stability classification is that of Pasquill originally developed in 1961, and modified in the same year by Gifford, and referred to as the Pasquill-Gifford stability class. They classified the atmospheric stability to categories; A, B, C, D, E and F [9, 12]. Atmospheric stability classes A, B, and C is light-hours stability classes. Class $\mathrm{A}$ is the most unstable and occurs when maximum incoming solar radiation is satisfied with little or no cloud cover and with relatively calm wind conditions. Stability classes B and C are also unstable atmospheric condition; while, B is moderately unstable but $\mathrm{C}$ is considered as slightly unstable. During daytimes when the insolation of the surface is strong enough to induce convective thermal motions, a mixed layer develops with an approximately constant potential temperature [13]. Neutral atmospheric condition (stability D) may occur either during the light hours or dark hours especially in the overcast conditions [14]. Stability classes E and F are nighttime stability categories [11, 15]. They refer to atmospheric conditions in which little energy is available in the atmosphere and the mechanical turbulence by the wind is the dominant. Class E is slightly atmospheric stability while $\mathrm{F}$ is the moderately stable condition.

Atmospheric boundary layer or Mixing Height $(\mathrm{MH})$ could be determined by practical method or/and modeling method. It is determined practically by measuring the profile of temperature and wind speed at different altitudes in the concerned area. The methods of profile measurements are radiosonde, Sodar, clear-air radar, and LIDAR [16, 17]. The practical method is often not available at each location. The other possibility is parameterizations or simple models with only few measured parameters such as temperature, solar radiation, wind speed, cloud cover, and day times. Several studies $[6,18]$ used simple models to estimate the height of mixing layer using the metrological measurements.

\subsection{The objectives}

The main objectives of this research are:

(1) Determine the atmospheric stabilities in Assiut city using surface metrological data,

(2) Modeling the height of mixing layer in the study area at different times and seasons,

(3) Exploit the results for the next study to estimate the dispersions of pollutants from sources.

\subsection{Observations and questions}

Dispersion modelling of pollutants requires essential parameters such as atmospheric stability and mixing height. Due to the deficiency of hourly metrological data in the development countries these factors are difficult to be estimated. In Assiut city, there are many sources of industrial pollution such as cement factories, fertilizer plant, and power station among others. These sources emit several types of contaminations to Assiut city. To study the amount of these pollutants and their dispersion on the atmosphere, atmospheric stability and thickness of mixing layers have to be modelled. Although, there are several known models can estimate these variable, these models are not available due to its high costs. In this study, a model developed before by the author [19] is used to model atmospheric stability and mixing height.

\subsection{Research hypothesis}

The study area is located in arid zone with relatively high temperature and low humidity. In addition, precipitation is rare thus the cloud density also is generally very low. From these conditions we can predict that, the dominant atmospheric stability during day hours is the category A especially in summer season. While the dominant category in night 
hours is expected to be the very unstable conditions (Instability F). Several similar studies concluded that the highest percent is the neutral conditions or stability D [17, 20, 21]. Most of these studies were in cold or rainy zones. The hypothesis of this study is that the dominant stability is also category D. Mixing heights are expected to be greater than 2000 $\mathrm{m}$ during day hours while in night hours MHs are expected to be less than $1000 \mathrm{~m}$.

\subsection{Methodology}

The methodology of this study is consisting of several steps. The first step is to get the essential metrological data. Analysis of the metrological data is carried out to get vision about the weather conditions in the study area. The Auxiliary Meteorological Model developed by Rabeiy 2010 [19] is used to determine the atmospheric stabilities within the study area. According to the results of stability categories, the model estimates the hourly thickness of mixing layer. Some arrangements are essential for the metrological data before feeding it to the model such as adding daily sunrise and sunset hours. The results of mixing height are investigated and tabulated according to each atmospheric category. Conclusion and some recommendations are added at the end of this paper.

\section{Materials and methods}

\subsection{Study area}

Assiut city (N $27^{\circ} 13^{\prime}$, E $\left.30^{\circ} 14^{\prime}\right)$ is located $375 \mathrm{Km}$ south of Cairo, the Capital of Egypt, and is the biggest city in Upper-Egypt region. Maximum temperature in the summer days reaches to $45{ }^{\circ} \mathrm{C}$ and minimum temperature in the winter ranges from 5 to $0{ }^{\circ} \mathrm{C}$. The study area is characterized as hot and calm wind location. Several industrial plants are installed around the city such as fertilizer plant, electrical energy station, petroleum refining, and cement plants among others. These industrial plants are the main sources of pollutants that can reach the city [22, 23].

\subsection{Atmospheric stability}

Atmospheric stabilities are determined in day hours using cloud cover and solar altitude [9, 13]. In this study the method suggested by Rabeiy 2010 [19] is used to determine the atmospheric stabilities during day hours. The method used the measured solar radiation and the wind speed instead of solar altitude and cloud cover. A modification to the incoming solar radiation ranges is suggested in this study to fit the metrological conditions in the hot areas as given in Table (1) [19, 21].

Table 1.

Atmospheric stability according to solar radiation $[19,21]$

\begin{tabular}{|c|c|c|c|c|c|c|}
\hline $\begin{array}{c}\text { Wind speed } \\
\text { At 10 m height }\end{array}$ & \multicolumn{9}{c|}{$\begin{array}{c}\text { Daytime } \\
\text { Amount of incoming solar radiation }\end{array}$} & \multicolumn{2}{c|}{$\begin{array}{c}\text { Night hours } \\
\text { Cloud cover }\end{array}$} \\
\hline $\mathrm{m} / \mathrm{s}$ & $>800$ & $800>$ SoI $>500$ & $500>$ SoI $>200$ & SoI $\leq 200$ & $\geq 50 \%$ & $<50 \%$ \\
\hline$<2$ & A & A & B & B & E & F \\
\hline $2-3$ & A & B & B & C & E & F \\
\hline $3-5$ & B & B & C & C & D & E \\
\hline $5-6$ & C & C & D & D & D & D \\
\hline$>6$ & C & D & D & D & D & D \\
\hline \multicolumn{7}{|l}{} \\
\hline
\end{tabular}




\subsection{Theoretical models}

This study estimates the mixing height from routinely measured metrological data. The proposed model to estimate $\mathrm{MH}$ at unstable conditions (stability A, B and C) is suggested by Giovannoni as in formula (1) [24]. Benkley \& Schulman [25] suggested formula (2) to compute the mechanical mixing height at neutral conditions which presented also by Arya [26]. Stable conditions $\mathrm{E}$ and $\mathrm{F}$ are night time conditions which means the convective force is not exist [18, 27]. Arya [26] proposed formula (3) to calculate the nocturnal mixing height.

$$
\begin{gathered}
H_{m}=-0.4 L\left(\frac{\omega_{*}}{U_{*}}\right)^{3} \\
H_{m}=0.185\left(\frac{U_{*}}{f}\right) \\
H_{m}=113.5+0.34\left(\frac{L U_{*}}{f}\right)^{\frac{1}{2}}
\end{gathered}
$$

Where $\mathrm{H}_{\mathrm{m}}$ is the mixing height, $\mathrm{L}$ is the Monin-Obukhov length, $\mathrm{U}_{*}$ is the friction velocity, $\mathrm{f}$ is the Coriolis factor, and $\omega_{*}$ is the convective velocity scale. The Obukhov length was firstly defined by Alexander Obukhov in 1946 to describe the effects of buoyancy on turbulent flows to determine the thickness of the atmospheric boundary layer [17]. Estimation of these factors such as Coriolis factor, Monin-Obukhov length and friction velocity is available in these sources [13, 18-20, 28]

\subsection{Metrological data}

The available metrological data processed in this study area are wind speed, temperature, pressure, cloud cover and solar radiation for the year of 2016. The measurements are taken hourly as given in Table (2) with total number of the processed data 8760 .

Table 2.

Example of available metrological data used in this study

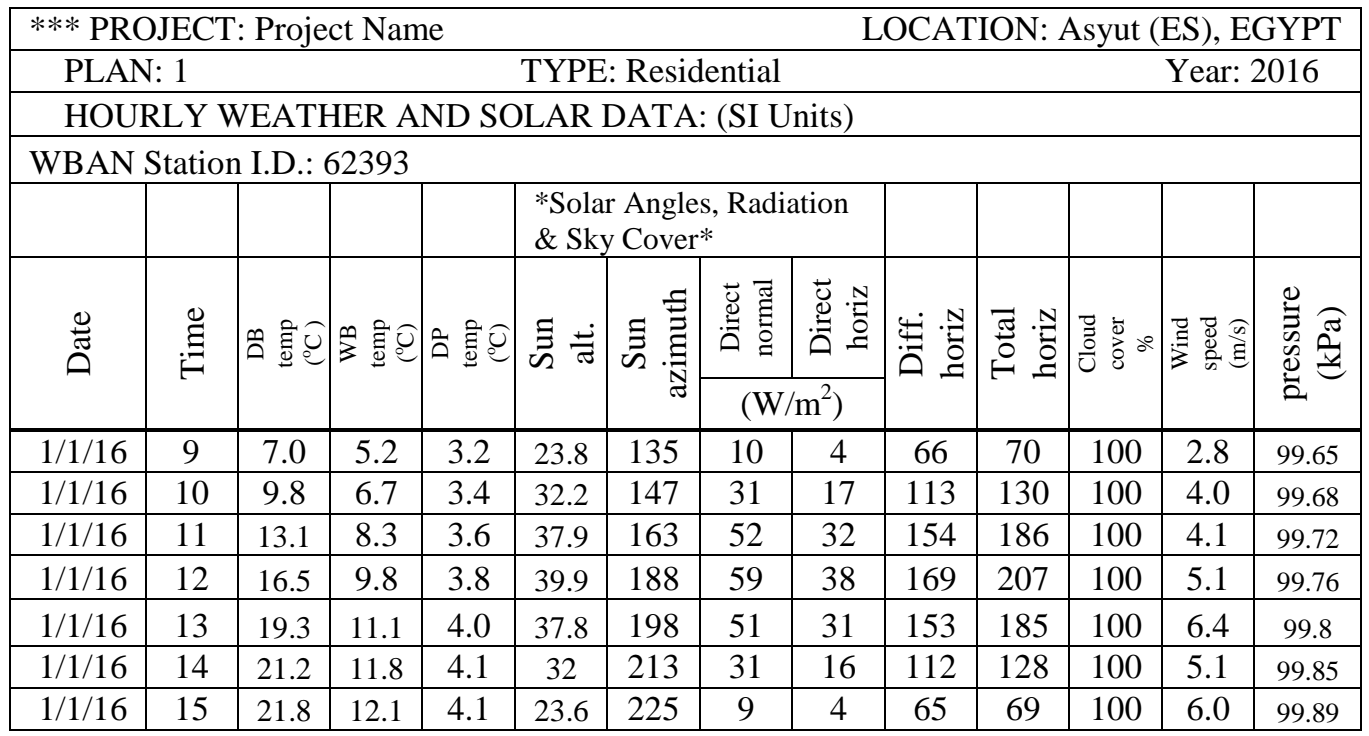

DB: dry bulb temperature, WB: wet bulb temperature, DP: dew point, Sun Alt: is the sun altitude 
JES, Assiut University, Faculty of Engineering, Vol. 45, No. 4, July 2017, pp.436-447

\section{Results and discussing}

Incoming solar radiation is the main agent that heats the earth surface. As the sun rise its energy increases and the heat of surface earth also increases which increases the MH during day hours. Incoming solar radiation in Assiut city is classified statistically in different seasons as given in Fig. 1a, b, and c. Maximum incoming solar radiation in summer reached to 1160 $\mathrm{W} / \mathrm{m}^{2}$ with average value of $1000 \mathrm{~W} / \mathrm{m}^{2}$. While minimum value during winter season was 100 $\mathrm{W} / \mathrm{m}^{2}$ and $530 \mathrm{~W} / \mathrm{m}^{2}$ during summer. Average measured incoming solar radiation is 1000,900 , 800, and 650 at summer, Spring, Fall, and Winter season respectively as presented in Fig 1c.

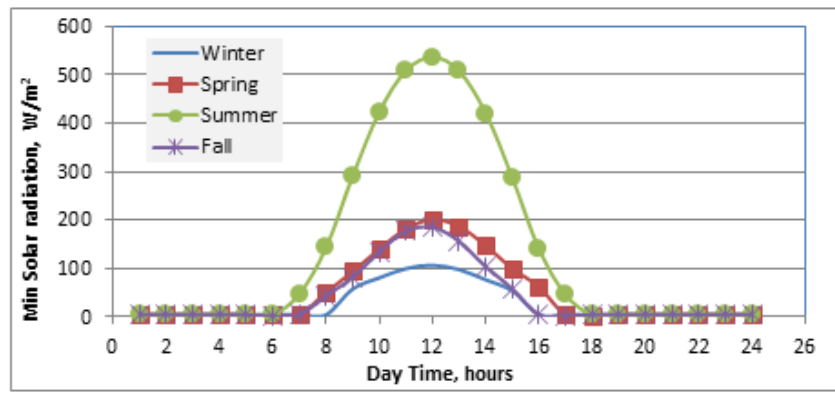

Fig. 1a

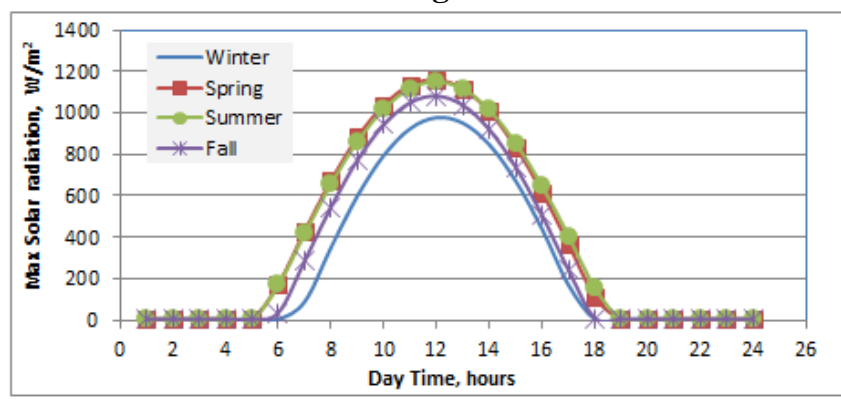

Fig. 1b

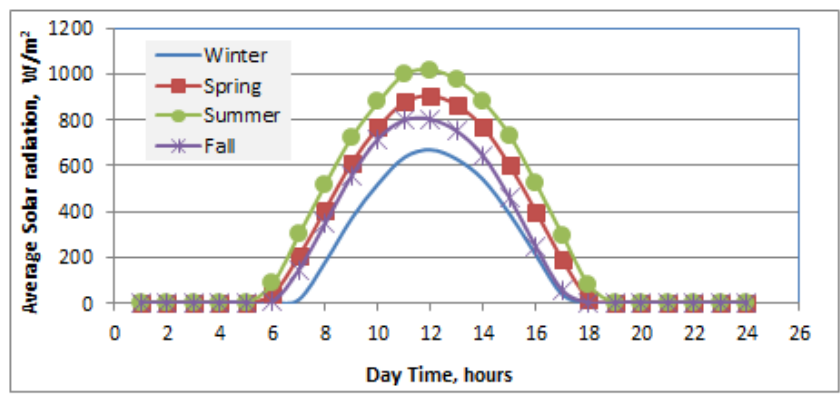

Fig. 1c

Fig. 1. durnal variation of solar radiation in Assiut city at different seasons a- minimum, bmaximum, and c- average value

Temperature is also analyzed during the study period 2016 in the investigated area and presented in Fig. 2a, b, and c. Temperature is indirect factor in evaluation of atmospheric stability and calculation of the mixing height. Maximum temperature in the summer and spring season is reaching to $45{ }^{\circ} \mathrm{C}$, while in winter season maximum value is $30{ }^{\circ} \mathrm{C}$. Minimum temperature was found in winter season and reached to -2 degree during the first hours of the morning as presented in Fig. $2 \mathrm{a}$. Average temperature in both Fall and Spring seasons are $30{ }^{\circ} \mathrm{C}$ while it is $36{ }^{\circ} \mathrm{C}$ and $20{ }^{\circ} \mathrm{C}$ in summer and winter season respectively. 


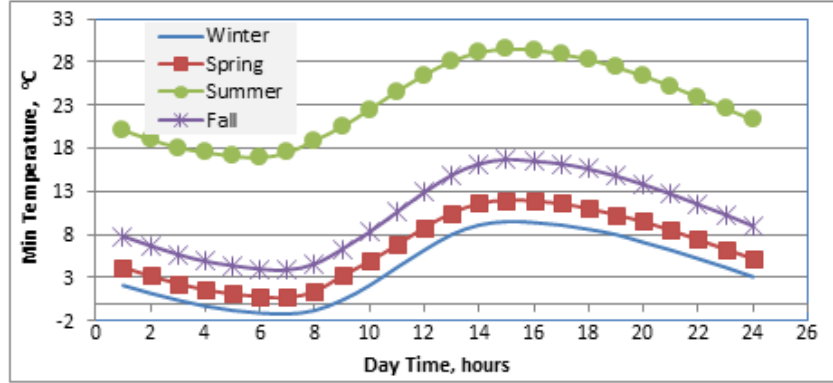

Fig. 2a

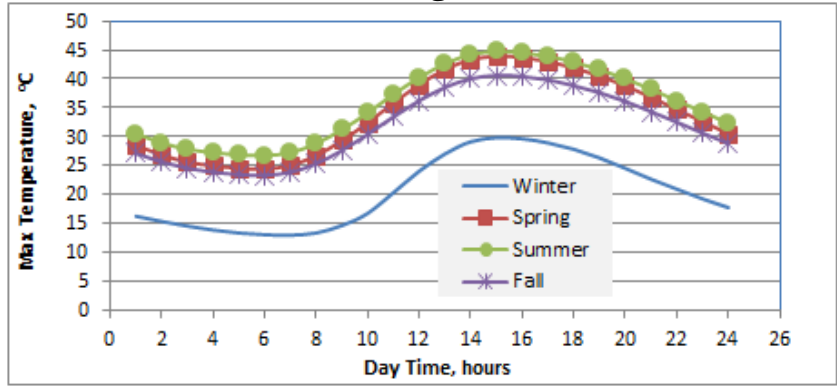

Fig. 2b

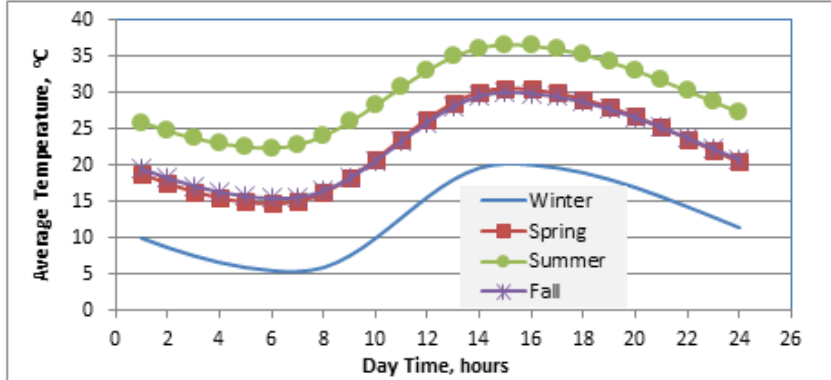

Fig. 2c

Fig. 2. durnal variation of temperature in Assiut city at different seasons, a- minimum, bmaximum, and c- average value

To determine the atmospheric stability in the investigated area, the Auxiliary Meteorological Model (AMM) provided by Rabeiy 2010 [19] is used. The model uses solar radiation and wind velocity ranges to determine the unstable conditions during day hours instead of sun altitude and cloud cover. During night hours the model uses the cloud cover and the wind speed to determine the stable or neutral conditions. The range of solar radiation is modified in this study to be suitable to the conditions of Assiut city as given in Table (1). The model also estimates the thickness of mixing layer according to equations 1 , 2 , and 3. Total number of the processed data was 8760 to determine hourly atmospheric stabilities and mixing height in the investigated area.

The result of hourly atmospheric stabilities for year 2016 in Assiut city is classified as day hours, night hours and for the whole year as given in Fig. 3a, b, and c. For the day hours, the dominant category is the stability A. As the study area is described as arid and hot location, this is explaining the high percentage of strongly instability conditions (A) with $66 \%$ during day hours. Analysis of solar radiation during day hours showed also that $75 \%$ of the processed data are greater than $823 \mathrm{~W} / \mathrm{m}^{2}$ as given in Table (3). The neutral 
condition in light hours occurs only during overcast conditions. As the study area is classified as arid location the cloud cover is rare during Summer, Fall, and Spring seasons. While, cloud cover is existing during Winter season for a few days. Therefore, the results given that the percentage of neutral stability $\mathrm{D}$ is small (16\%).

During night hours the dominant stability is F (very unstable condition) as illustrated in Fig. 1b. The mixing layer during dark hours is created due to the mechanical effect of the wind shear. Assiut city is known as not only arid but also calm wind area as presented in table (4). The F stability happens in the case of calm wind and clear sky. From Table (4) we can notice that wind speed is less than $2 \mathrm{~m} / \mathrm{s}$ for $75 \%$ of the monitored values during night hours. For cloud $80 \%$ of the observed values are less than $48 \%$. This statistics interprets the large percentage of stability F (66\%) during night hours. A neutral condition is also depending mainly on the overcast weather and high wind speed. Therefore, stability $\mathrm{D}$ has the smallest percentage during night hours as given in Fig. $3 \mathrm{~b}$.

According to the statistics for whole data, the dominant stability condition is the very unstable category $\mathrm{F}$ with percentage of $37 \%$ as presented in Fig. 1c. The percentage of unstable conditions is $38 \%$ of the total processed data, while the neutral conditions formed $11 \%$ of the total processed data.
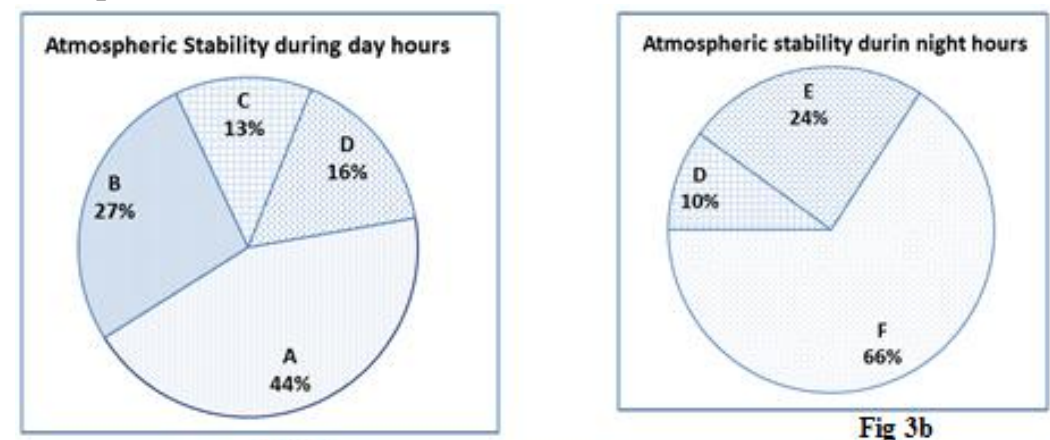

Fig 3a

Fig 3b

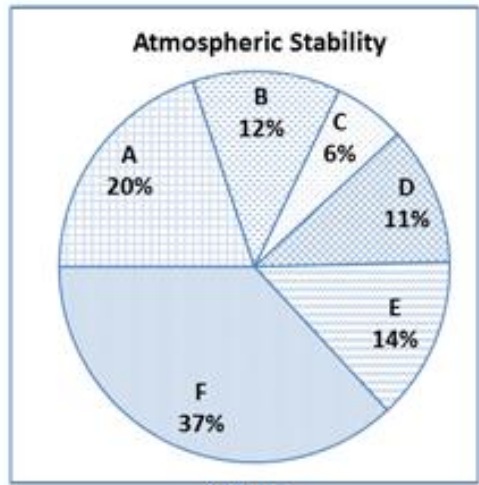

Fig $3 c$

Fig. 3. atmospheric stabilities a-during day hours, b-during night hours, and c- for the whole year (2016). 
Table 3.

solar radiation $\mathrm{W} / \mathrm{m}^{2}$ during day hours and according to atmospheric stabilities (Unstable and neutral conditions)

\begin{tabular}{|l|r|c|c|c|c|r|}
\hline \multicolumn{1}{|c|}{ Agent } & \multicolumn{1}{c|}{ Total } & A & B & C & D & $\begin{array}{r}\text { Wind } \\
\text { speed }\end{array}$ \\
\hline Max & 1160 & 1160 & 1114 & 1102 & 611 & 6.6 \\
\hline Average & 567.2 & 807 & 559 & 269 & 114 & 1.4 \\
\hline Min & 11 & 500 & 301 & 151 & 11 & 0 \\
\hline StDv & 310.6 & 174 & 218 & 134 & 103 & 1.2 \\
\hline Q1 & 303 & 658 & 731 & 193 & 42 & 0.4 \\
\hline Q3 & 823 & 952 & 379 & 286 & 143 & 2.11 \\
\hline
\end{tabular}

Table 4.

Wind speed and cloud cover during night hours

\begin{tabular}{|l|c|c|}
\hline & Wind Speed, $\mathrm{m} / \mathrm{s}$ & Cloud cover \\
\hline Max & 7.11 & 98.60 \\
\hline Average & 1.36 & 36.06 \\
\hline Min & 0.00 & 9.83 \\
\hline stdv & 1.19 & 16.43 \\
\hline Q1 & 0.37 & 23.73 \\
\hline Q3 & 2.07 & 44.11 \\
\hline Percentile, 80 & 2.29 & 48.16 \\
\hline
\end{tabular}

Diurnal of the average estimated $\mathrm{MH}$ at different seasons is examined and presented in Fig (4). In this figure, we can see that, mixing height during night hours is less than $500 \mathrm{~m}$ in all seasons. Nocturnal boundary layer is the smallest in winter season and is the largest in summer season. During light hours, mixing height at summer is larger than any other season due to the strong of solar energy. Spring and Fall seasons have relatively equal average mixing heights during day hours. Mixing height in winter has the smallest values with the range from $1000 \mathrm{~m}$ to $1500 \mathrm{~m}$. From Fig (4) we can notice that, mixing height is gradually increasing from the morning hours to reach the maximum values in the late afternoon for all seasons.

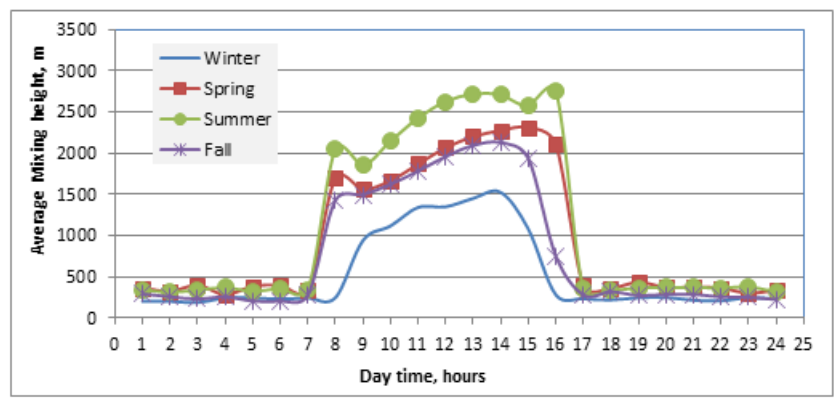

Fig. 4. diurnal average values of mixing height at the four seasons

Mixing height was also classified according to the type of atmospheric stabilities as given in Table (5). For stability A (very unstable conditions), $75 \%$ of $\mathrm{MH}$ is greater than $1500 \mathrm{~m}$, while $48 \%$ and $23 \%$ is greater than $1500 \mathrm{~m}$ for stabilities B and C respectively. 
At neutral conditions (stability D) only $5 \%$ of the estimated $\mathrm{MH}$ is greater than $1500 \mathrm{~m}$ while zero $\%$ of mixing height is greater than $1500 \mathrm{~m}$ in case of stable conditions (stabilities $\mathrm{E}$ and F). In other words, $\mathrm{MH}$ at stable conditions is $64 \%$ less than $500 \mathrm{~m}$ for stability E and $90 \%$ less than $500 \mathrm{~m}$ for stability F.

Table 5.

Frequency and cumulative frequency of HM according to atmospheric stabilities

\begin{tabular}{|c|l|r|l|r|r|r|r|r|r|r|r|r|r|}
\hline Stability & \multicolumn{2}{|c|}{ A } & \multicolumn{2}{|c|}{ B } & \multicolumn{2}{|c|}{ C } & \multicolumn{3}{|c|}{ D } & \multicolumn{3}{|c|}{ E } \\
\hline MH range & Fre. & Cum\% & Fre. & Cum\% & Fre. & Cum\% & Fre. & Cum\& & Fre. & Cum\% & Fre. & Cum\% \\
\hline $0-500$ & 8 & 0.5 & 268 & 25.0 & 274 & 52.3 & 617 & 64.0 & 759 & 64.2 & 2923 & 90.4 \\
\hline $500-700$ & 0 & 0.5 & 28 & 27.6 & 51 & 62.0 & 110 & 75.4 & 37 & 67.3 & 223 & 97.3 \\
\hline $700-900$ & 11 & 1.1 & 17 & 29.2 & 13 & 64.5 & 78 & 83.5 & 163 & 81.1 & 87 & 100.0 \\
\hline $900-1100$ & 83 & 5.9 & 82 & 36.9 & 23 & 68.9 & 72 & 91.0 & 127 & 91.8 & 0 & 100.0 \\
\hline $1100-1300$ & 147 & 14.3 & 91 & 45.3 & 16 & 72.0 & 23 & 93.4 & 72 & 97.9 & 0 & 100.0 \\
\hline $1300-1500$ & 200 & 25.8 & 79 & 52.7 & 25 & 76.7 & 8 & 94.2 & 24 & 99.9 & 0 & 100.0 \\
\hline $1500-1700$ & 197 & 37.1 & 99 & 62.0 & 21 & 80.7 & 8 & 95.0 & 0 & 99.9 & 0 & 100.0 \\
\hline $1700-1900$ & 159 & 46.2 & 81 & 69.5 & 24 & 85.3 & 6 & 95.6 & 1 & 100.0 & 0 & 100.0 \\
\hline $1900-2100$ & 166 & 55.8 & 66 & 75.7 & 11 & 87.4 & 1 & 95.8 & 0 & 100.0 & 0 & 100.0 \\
\hline $2100-2300$ & 155 & 64.7 & 73 & 82.5 & 11 & 89.5 & 3 & 96.1 & 0 & 100.0 & 0 & 100.0 \\
\hline $2300-2500$ & 201 & 76.2 & 80 & 90.0 & 16 & 92.6 & 5 & 96.6 & 0 & 100.0 & 0 & 100.0 \\
\hline$>2500$ & 414 & 100.0 & 108 & 100.0 & 39 & 100.0 & 33 & 100.0 & 0 & 100.0 & 0 \\
\hline No of data & 1741 & & 1072 & & 524 & & 964 & & 1183 & & 3233 & 100.0 \\
\hline
\end{tabular}

\section{Conclusion}

Atmospheric stabilities and mixing height are essential parameters in studying dispersion of pollutants from different sources. In this study the meteorological data is used to determine the types of atmospheric stabilities and the thickness of the mixing layer in Assiut city for year 2016. The results showed that dominant stability during day hours especially in summer season is the very unstable category (instability A) while very stable conditions (stability F) are the dominant during night hours. Mixing height during day hours tends to be relatively high values. Therefore pollutants from stacks in the study area have little effects on surface earth during day hours. While in the night hours, inversion layer is created with mixing height less than $200 \mathrm{~m}$ in several cases that increases the concentrations of pollution on the ground surface.

\section{Recommendation}

According to this study, the author recommended that the industrial process decrease its activity during night hours as can as possible or at least working with the minimum load of the production. In the next study, a Gaussian dispersion plume model will be used to estimate the amount of pollutants emitted from point sources in Assiut city. The results of atmospheric stabilities and mixing height from this study will be exploited as input data in the next investigation. 


\section{Acknowledgement}

I would like gratefully thank Professor Ahmed Mohamed Hamza; professor of Mechanical Engineering, Assiut University. He provided this work with the essential metrological data of the investigated area.

\section{REFERENCES}

[1] Hanna, S.R. and J.C. Chang, Boundary-layer parameterizations for applied dispersion modeling over urban areas. Boundary-Layer Meteorology, 1992. 58(3): p. 229-259.

[2] Gorle, J.M.R. and N.R. Sambana, Dispersion modeling of thermal power plant emissions on stochastic space. Theoretical and Applied Climatology, 2016. 124(3-4): p. 1119-1131.

[3] Albani, R.A.S., F.P. Duda, and L.C.G. Pimentel, On the modeling of atmospheric pollutant dispersion during a diurnal cycle: A finite element study. Atmospheric Environment, 2015. 118: p. 19-27.

[4] Zaïdi, H., et al., Effect of Atmospheric Stability on the Atmospheric Dispersion Conditions Over a Industrial Site Surrounded by Forests, in Air Pollution Modeling and its Application XXII, D.G. Steyn, P.J.H. Builtjes, and R.M.A. Timmermans, Editors. 2014, Springer Netherlands: Dordrecht. p. 733-737.

[5] Machefaux, E., et al., An experimental and numerical study of the atmospheric stability impact on wind turbine wakes. Wind Energy, 2016. 19(10): p. 1785-1805.

[6] Fatogoma, O. and R.B. Jacko, A model to estimate mixing height and its effects on ozone modeling. Atmospheric Environment, 2002. 36(22): p. 3699-3708.

[7] Baxter, R., Determination of mixing heights from data collected during the 1985 SCCCAMP field program. Journal of Applied meteorology, 1991. 30(5): p. 598-606.

[8] Lotteraner, C. and M. Piringer, Mixing-Height Time Series from Operational Ceilometer Aerosol-Layer Heights. Boundary-Layer Meteorology, 2016. 161(2): p. 265-287.

[9] Beychok, M.R., Fundamentals of stack gas dispersion. 1994: Milton R. Beychok Irvine.

[10] Hernandez-Ramirez, G., et al., Quantifying atmospheric stability conditions at a swine facility and an adjacent corn field in Iowa, USA. Theoretical and Applied Climatology, 2011. 105(3): p. 495-503.

[11] Omori, Y. and H. Nagahama, Radon as an Indicator of Nocturnal Atmospheric Stability: A Simplified Theoretical Approach. Boundary-Layer Meteorology, 2016. 158(2): p. 351-359.

[12] Murphy, J.F. and K.A. Zimmermann, Making RMP hazard assessment meaningful. Process Safety Progress, 1998. 17(4): p. 238-242.

[13] van Dop, H., Atmospheric Distribution of Pollutants and Modelling of Air Pollution Dispersion, in Air Pollution. 1986, Springer Berlin Heidelberg: Berlin, Heidelberg. p. 107147.

[14] Patton, E.G., et al., Atmospheric Stability Influences on Coupled Boundary Layer and Canopy Turbulence. Journal of the Atmospheric Sciences, 2016. 73(4): p. 1621-1647.

[15] Carras, J.N., The Transport and Dispersion of Plumes from Tall Stacks, in Environmental Aspects of Trace Elements in Coal, D.J. Swaine and F. Goodarzi, Editors. 1995, Springer Netherlands: Dordrecht. p. 146-177.

[16] Hicks, M., R. Sakai, and E. Joseph, The Evaluation of a New Method to Detect Mixing Layer Heights Using Lidar Observations. Journal of Atmospheric and Oceanic Technology, 2015. 32(11): p. 2041-2051.

[17] Schutt, M., H. Seim, and Ieee, Impact of Stability on the Atmospheric Boundary Layer, in Oceans 2015 - Mts/Ieee Washington. 2015.

[18] Lena, F. and F. Desiato, Intercomparison of nocturnal mixing height estimate methods for urban air pollution modelling. Atmospheric Environment, 1999. 33(15): p. 2385-2393. 
[19] Rabeiy, R.E., Spatial modeling of heavy metal pollution of forest soils in an historical mining area using geostatistical methods and air despersion modeling. 2010, Universitätsbibliothek Clausthal: Clausthal-Zellerfeld.

[20] Khan, S.M. and R.W. Simpson, Modelling mixing height from routinely measured surface and upper air meteorological data. Environmental Modeling \& Assessment, 1997. 2(3): p. 191-200.

[21] Morbidelli, R., et al., Atmospheric Stability and Meteorological Scenarios as Inputs to Air Pollution Transport Modeling. Water, Air, \& Soil Pollution, 2011. 218(1): p. 275-281.

[22] Bady, M., ASSESSMENT OF WIND CONDITIONS IN ASSIUT CITY, EGYPT USING LONG-TERM WIND MEASUREMENTS.

[23] Hill, T. Assiut Barrage, to rehabilitate or to rebuild. in Improvements in reservoir construction, operation and maintenance: Proceedings of the 14th Conference of the British Dam Society at the University of Durham from 6 to 9 September 2006. 2006. Thomas Telford Publishing.

[24] Giovannoni, J.-M., Modeling of $\mathrm{SO}, \mathrm{Pb}$ and $\mathrm{Cd}$ atmospheric deposition over a one-year period. Atmospheric Environment. Part A. General Topics, 1993. 27(12): p. 1793-1808.

[25] Benkley, C.W. and L.L. Schulman, Estimating hourly mixing depths from historical meteorological data. Journal of Applied Meteorology, 1979. 18(6): p. 772-780.

[26] Arya, S., Parameterizing the height of the stable atmospheric boundary layer. Journal of Applied Meteorology, 1981. 20(10): p. 1192-1202.

[27] Yu, T.-W., Determining height of the nocturnal boundary layer. Journal of Applied Meteorology, 1978. 17(1): p. 28-33.

[28] 28.Holtslag, A. and A. Van Ulden, A simple scheme for daytime estimates of the surface fluxes from routine weather data. Journal of climate and Applied Meteorology, 1983. 22(4): p. 517-529. 
ان تعيين الاستقرار الجوي وكذللك ارتفاع طبقة خلط الملوثات بـالهو اء مـن العوامل الرئيسية في در اسـة

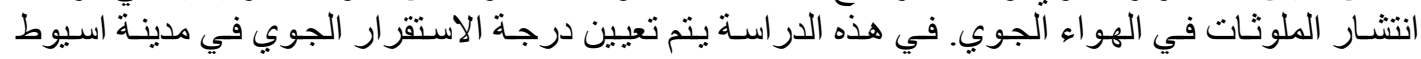

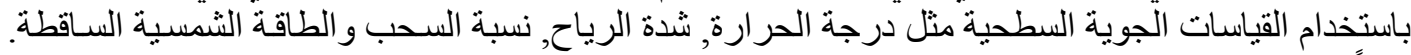

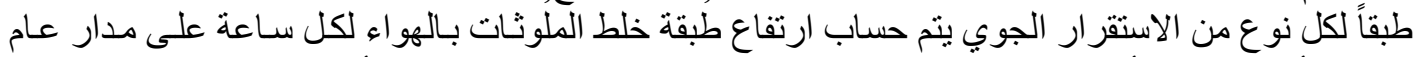

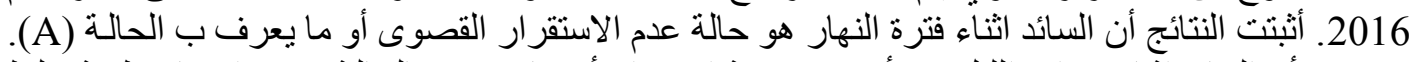

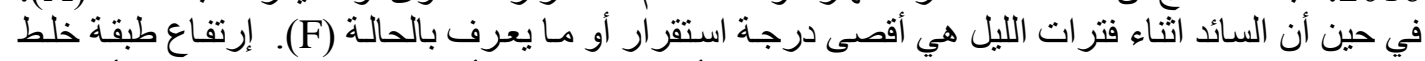

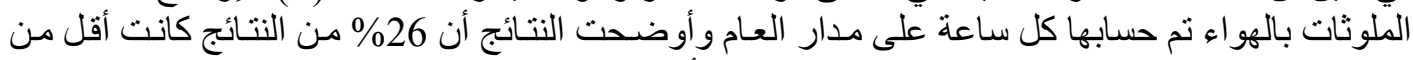

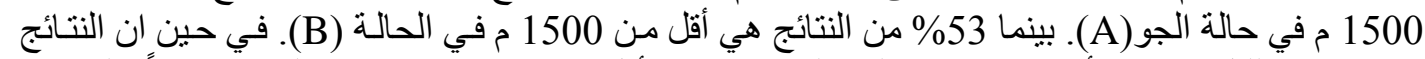

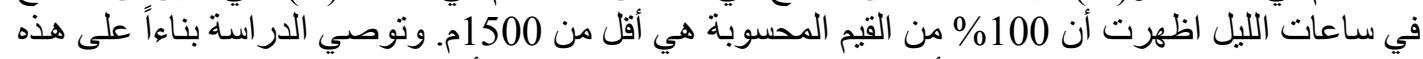

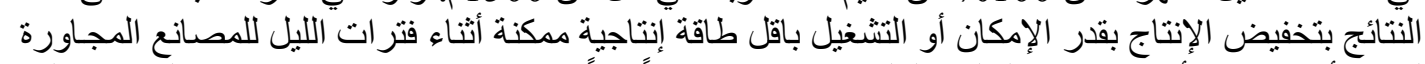

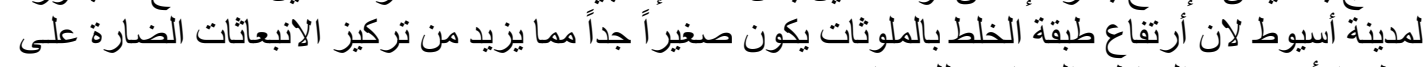

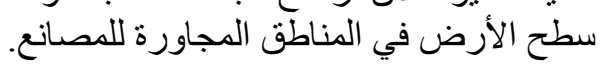

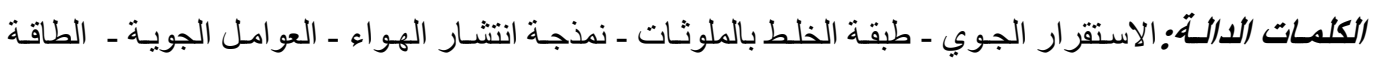

